\title{
In Vitro Differentiation Potential of Human Placenta Derived Cells into Skin Cells
}

\author{
Ruhma Mahmood, ${ }^{1,2}$ Mahmood S. Choudhery, ${ }^{1,3}$ Azra Mehmood, \\ Shaheen N. Khan, ${ }^{1}$ and Sheikh Riazuddin ${ }^{1,4}$ \\ ${ }^{1}$ National Center of Excellence in Molecular Biology, University of the Punjab, Lahore, Pakistan \\ ${ }^{2}$ University of Health Sciences, Lahore, Pakistan \\ ${ }^{3}$ Tissue Engineering and Regenerative Medicine Laboratory, King Edward Medical University, Lahore, Pakistan \\ ${ }^{4}$ Allama Iqbal Medical College, Lahore, Pakistan \\ Correspondence should be addressed to Ruhma Mahmood; ruhma_mahmood@yahoo.com
}

Received 9 March 2015; Revised 1 June 2015; Accepted 3 June 2015

Academic Editor: Hung-Fat Tse

Copyright (C) 2015 Ruhma Mahmood et al. This is an open access article distributed under the Creative Commons Attribution License, which permits unrestricted use, distribution, and reproduction in any medium, provided the original work is properly cited.

\begin{abstract}
Skin autografting is the most viable and aesthetic technique for treatment of extensive burns; however, this practice has potential limitations. Harvesting cells from neonatal sources (such as placental tissue) is a simple, inexpensive, and noninvasive procedure. In the current study authors sought to evaluate in vitro potential of human placenta derived stem cells to develop into skin-like cells. After extensive washing, amniotic membrane and umbilical cord tissue were separated to harvest amniotic epithelial cells (AECs) and umbilical cord mesenchymal stem cells (UC-MSCs), respectively. Both types of cells were characterized for the expression of embryonic lineage markers and their growth characteristics were determined. AECs and UC-MSCs were induced to differentiate into keratinocytes-like and dermal fibroblasts-like cells, respectively. After induction, morphological changes were detected by microscopy. The differentiation potential was further assessed using immunostaining and RT-PCR analyses. AECs were positive for cytokeratins and E-Cadherin while UC-MSCs were positive for fibroblast specific makers. AECs differentiated into keratinocyteslike cells showed positive expression of keratinocyte specific cytokeratins, involucrin, and loricrin. UC-MSCs differentiated into dermal fibroblast-like cells indicated expression of collagen type 3, desmin, FGF-7, fibroblast activation protein alpha, procollagen-1, and vimentin. In conclusion, placenta is a potential source of cells to develop into skin-like cells.
\end{abstract}

\section{Introduction}

Deep burn injuries such as full-thickness wounds require restoration of both the epidermal and the dermal layers of the skin. In normal wound healing, migration and proliferation of keratinocytes from the wound edges result in reepithelization [1] while dermis restoration is dependent on growth factor secretion by macrophages, platelets, and fibroblasts and by fibroblast proliferation [2]. These processes are defective in patients with full-thickness burn injuries due to damage to both layers. Although skin autografting is the most viable and aesthetic technique for the treatment of such injuries, this practice has potential limitations that exposes the donor to additional wounds. Stem cells present in various adult and neonatal tissues show huge potential for tissue engineering and regenerative medicine applications. Harvesting cells from placental tissue is advantageous as it poses no risk to donor, is noninvasive procedure, and is a readily available cell source. Although cord tissue and amniotic membrane of placenta have been recognized as a promising source of stem cells, their therapeutic potential in wound healing has not yet been widely investigated. In the present study, we have evaluated the in vitro differentiation potential of stem cells isolated from cord tissue and amniotic membrane of placenta into skin-like cells, that is, keratinocytes and fibroblasts.

In USA alone, there are 500,000 burn injuries per year due to which approximately 3500 deaths occur annually and this ratio is even higher in developing countries [3]. In Pakistan, burns are the second leading cause of disability and the 11th leading cause of premature deaths [4]. These facts thus necessitate an urgent need for the identification of cell sources that are plentiful and safe and with no ethical issues. 
Human placenta is one such source that can provide cells for therapeutic strategies. Additionally, immunomodulatory and immunosuppressive properties of placenta derived cells make it an ideal option for use in allogeneic therapy.

In the current study amniotic membrane and umbilical cord tissue were isolated and processed to obtain AECs and UC-MSCs, respectively. Both types of cells were characterized for cell surface and embryonic lineage markers. Further, growth characteristics were determined by analyzing plating efficiency and number and time of population doubling. AECs and UC-MSCs were induced to differentiate in vitro into keratinocytes and fibroblasts, respectively. Differentiated cells displayed significant morphological alterations. Differentiation into keratinocytes- and fibroblast-like cells was further confirmed using immunostaining and reverse transcriptase polymerase chain reaction (RT-PCR). The results of current study suggest that pure populations of AECs and UC-MSCs isolated from human placenta are capable of in vitro differentiation into functional skin cells and thus can be implied for regenerating damaged tissue.

\section{Materials and Methods}

2.1. Collection of Placenta. Human placentas $(n=15)$ for the isolation of AECs and UC-MSCs were obtained from the maternity hospitals after full-term, uncomplicated elective cesarean deliveries. All samples were collected from donors who were negative for HBV, HCV, and HIV. The umbilical cord tissue and amniotic membrane were separated in sterilized conditions and processed within two hours. Informed consent was obtained from each donor prior to collection. All protocols used in this study were approved by the institution review board (IRB) at the National Centre of Excellence in Molecular Biology (CEMB), University of the Punjab, Lahore, Pakistan. The reagents used in the study were purchased from Sigma Aldrich, USA; Invitrogen, USA; Abcam, UK and Santa Cruz Biotechnology USA. A complete list of reagents and antibodies have been given in Table 2 .

\subsection{Isolation of Cells}

2.2.1. Amniotic Epithelial Cells (AECs). AECs from amniotic membrane tissue were obtained by direct explant technique [5]. Briefly, amniotic membrane was peeled off from chorion and washed several times with sterile phosphate buffered saline (PBS, Sigma Aldrich, USA). Approximately $1 \mathrm{~cm}^{2}$ pieces of amniotic membrane were explanted in $25 \mathrm{~cm}^{2} \mathrm{cul}-$ ture flask in AECs expansion medium, that is, DMEM supplemented with $10 \%$ FCS, $100 \mathrm{U} / \mathrm{mL}$ penicillin, and $100 \mathrm{mg} / \mathrm{mL}$ streptomycin (Sigma Aldrich, USA) and then incubated in a humidified incubator at $37^{\circ} \mathrm{C}$ and $5 \% \mathrm{CO}_{2}$. Medium was first replaced after 48 hours without disturbing the tissue pieces and after every 3 days thereafter for 10-14 days. Tissue pieces were removed and cells were harvested using 0.25\% trypsinEDTA (Sigma Aldrich, USA) and counted with hemocytometer and 75,000 cells were replated in $75 \mathrm{~cm}^{2}$ culture flasks. Passage 2 cells were then characterized by plating $1 \times 10^{4}$ cells per well in a multiwall plate and were incubated with primary antibodies for CD45, CK8, CK18, CK19 (Abcam, UK), and
E-Cadherin (Santa Cruz Biotechnology, USA) overnight at $4^{\circ} \mathrm{C}$. The cells were washed with PBS and then incubated with respective secondary antibodies at room temperature.

2.2.2. Umbilical Cord Mesenchymal Stem Cells (UC-MSCs). UC-MSCs were isolated using a nonenzymatic digestion technique as described [6]. Briefly 5-inch cord tissue piece was extensively washed with PBS containing $100 \mathrm{U} / \mathrm{mL}$ penicillin and $100 \mathrm{mg} / \mathrm{mL}$ streptomycin (Sigma Aldrich, USA). Tissue piece was cut and minced to obtain small fine pieces that were then placed in a $25 \mathrm{~cm}^{2}$ culture flask (Corning Inc., USA). $5 \mathrm{~mL}$ of UC-MSCs expansion medium (DMEM supplemented with $10 \%$ FBS, $100 \mathrm{U} / \mathrm{mL}$ penicillin, and $100 \mathrm{mg} / \mathrm{mL}$ streptomycin (Sigma Aldrich, USA)) was added in the culture flask and tissue pieces were evenly distributed. The culture flasks were incubated at $37^{\circ} \mathrm{C}$ and $5 \%$ $\mathrm{CO}_{2}$ in humidified incubator. Cell outgrowth was observed 34 days after culturing and tissue pieces were removed after 810 days. Cell colonies appeared in the culture within 2 weeks. The cells were harvested using trypsin-EDTA and 75,000 cells were replated in new $75 \mathrm{~cm}^{2}$ culture flasks. At passage 2, these cells were incubated with primary antibodies for CD45, CD49, CD73, and CD90 (Abcam, UK) overnight at $4^{\circ} \mathrm{C}$. Primary antibodies were removed and cells were incubated with secondary antibodies at room temperature.

\subsection{Growth Characteristics}

2.3.1. Plating Efficiency. Plating efficiency was determined as reported previously [7]. Briefly each type of cells at second passage was seeded in $25 \mathrm{~cm}^{2}$ culture flasks at a concentration of 50 cells per $\mathrm{cm}^{2}$. Cultures were fed with fresh medium after every 3 days till 2 weeks, after which the cells were fixed with methanol and stained with crystal violet dye (Sigma Aldrich, USA) overnight at room temperature. The resultant colonies were counted and percentage plating efficiency was calculated by using following formula:

$$
\% \text { plating efficiency }=\left(\frac{\text { colonies counted }}{\text { number of cells seeded }}\right)
$$

$$
\times 100 \text {. }
$$

2.3.2. Number and Time of Population Doublings. Both AECs and UC-MSCs were serially passaged under standard culture conditions for analysis of cumulative population doublings and doubling time. Briefly, at first passage, $1 \times 10^{5}$ cells were counted and plated in a $25 \mathrm{~cm}^{2}$ culture flask. At $80 \%-90 \%$ confluency, cells were subcultured, counted, and plated at the same density as described above. This procedure was repeated for several passages until the cells fail to reach $90 \%$ confluency even after 3 weeks [7]. Following formulae were used to determine cumulative population doublings and doubling time [6]:

$$
\begin{aligned}
\mathrm{cPDs} & =\log \left(\frac{N}{N o}\right) \times 3.3, \\
\mathrm{DT} & =\frac{\mathrm{CT}}{\mathrm{cPDs}},
\end{aligned}
$$


TABLE 1: List of used primers and their sequences.

\begin{tabular}{|c|c|c|c|}
\hline Number & Markers & $5^{\prime}-3^{\prime}$ sequence & Product size \\
\hline \multirow{2}{*}{1} & \multirow{2}{*}{ Beta actin } & CGCATGGGTCAGAAGGATTC (F) & \multirow{2}{*}{137} \\
\hline & & TAGAAGGTGTGGTGCCAGATTT (R) & \\
\hline \multirow{2}{*}{2} & \multirow{2}{*}{ CD29 } & GCAGTTGGTTTTGCGATTAAG (F) & \multirow{2}{*}{233} \\
\hline & & AAGGCATCACAGTCTTTTCCA (R) & \\
\hline \multirow{2}{*}{3} & \multirow{2}{*}{ CD44 } & AGAAAAATGGTCGCTACAGCA (F) & \multirow{2}{*}{571} \\
\hline & & CTGAAGTGCTGCTCCTTTCAC (R) & \\
\hline \multirow{2}{*}{4} & \multirow{2}{*}{ CD45 } & CACTGCAGGGATGGATCTCA (F) & \multirow{2}{*}{312} \\
\hline & & ACTCGTGGGTTCAGAACCTTCA (R) & \\
\hline \multirow{2}{*}{5} & \multirow{2}{*}{ CD73 } & ACAACAGCCAACTGCTTTCAT (F) & \multirow{2}{*}{154} \\
\hline & & TTCTCAGCATTCCCGAAAT (R) & \\
\hline \multirow{2}{*}{6} & \multirow{2}{*}{ CD90 } & ATGAACCTGGCCATCAGCATGC (F) & \multirow{2}{*}{344} \\
\hline & & CACGAGGTGTTCTGAGCCAGCA (R) & \\
\hline \multirow{2}{*}{7} & \multirow{2}{*}{ CK1 } & GGAGGAGGAGGTGGTAGATTTT (F) & \multirow{2}{*}{388} \\
\hline & & GAGGTTGCTGATGTATGACTCG (R) & \\
\hline \multirow{2}{*}{8} & \multirow{2}{*}{ CK10 } & GAGCAAGGAACTGACTACAG (F) & \multirow{2}{*}{249} \\
\hline & & CTCGGTTTCAGCTGCAATCT (R) & \\
\hline \multirow{2}{*}{9} & \multirow{2}{*}{ CK14 } & TGCTATTGGTGTCAGGGAAG (F) & \multirow{2}{*}{277} \\
\hline & & GTGGCAAGGTTCTTTTCTCC (R) & \\
\hline \multirow{2}{*}{10} & CK16 & ATCGTTAGAGCCAAGCAGGA (F) & 228 \\
\hline & CNIO & GAGAAGCGAGAGGGAGGTGAC (R) & 220 \\
\hline 11 & CK18 & CACACTCACGGAGCTGAGAC (F) & 168 \\
\hline & & GCCAGCTCTGACTCCAGATG (R) & \\
\hline 12 & CK19 & GCCTGGCTGCAGATGACT (F) & 157 \\
\hline & & AGCTCCTCCTTCAGGCTCTC (R) & \\
\hline 13 & Collagen-3 & GTTGACCCTAACCAAGGATGCA (F) & 203 \\
\hline & & GGAAGTTCAGGATTGCCGTAG (R) & \\
\hline 14 & Vimentin & CTGCGGGAGTAGTTGGAAAGT (F) & 241 \\
\hline 14 & vimentin & GGAAATGGGACAAAACATCCT (R) & 241 \\
\hline 15 & FGF 7 & TGGTGAAGTTCATGGATGTCTATC (F) & 212 \\
\hline & & CACAGGATGGCTTGAAGATGTA (R) & 212 \\
\hline 16 & Desmin & CATCCTCAAGAAGGTGTTGGAG (F) & 112 \\
\hline 10 & 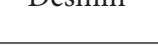 & CAAAGAGACGTGGGACGAGT (R) & 112 \\
\hline 17 & Oct-4 & GGCGTTCTCTTTGGAAAGGTGTTC (F) & 145 \\
\hline & & CTCGAACCACATCCTTCTCT (R) & \\
\hline 18 & Nanog & GGACGCGTGGGGGCTGGAGAC (F) & 174 \\
\hline & & GGCTCGAGGGGGACCAGGAAG (R) & \\
\hline 19 & SSEA4 & CCGCGTCAAGAGGCCCATGAA (F) & 148 \\
\hline 19 & SSEA4 & CCCGCTTCTCGGTCTCGGACAA (R) & 148 \\
\hline
\end{tabular}

where cPDs represents cumulative population doublings, $\mathrm{No}$ is the number of cells plated and $N$ is the number of cells harvested, DT is doubling time, and CT is total time.

\subsection{Differentiation Assays}

2.4.1. Differentiation of Amniotic Epithelial Cells into Keratinocyte-Like Cells. AECs were obtained as described above and $1 \times 10^{4}$ cells at passage 2 were plated in 6-well plates in expansion medium. When cells attain their normal morphology, differentiation process was initiated by replacing expansion medium with keratinocyte differentiation medium (DMEM + HAM F12 (3:1), Sigma Aldrich, USA) supplemented with $10 \% \mathrm{FCS}, 100 \mathrm{IU} / \mathrm{mL}$ penicillin, $100 \mathrm{mg} / \mathrm{mL}$ streptomycin, $0.5 \mathrm{mg} / \mathrm{mL}$ hydrocortisone, $1 \%$ insulin transferrin (Sigma Aldrich, USA), and $15 \mathrm{ng} / \mathrm{mL}$ keratinocytes growth factor (Invitrogen, USA). Keratinocytes differentiation medium was replaced twice a week for 15 days. Cells grown in AECs expansion medium for similar time points served as control. After 15 days, differentiation of epithelial cells into keratinocyteslike cells was assessed using immunohistochemistry and RTPCR analysis. 
TABLE 2: List of reagents and antibodies.

\begin{tabular}{|c|c|c|}
\hline Sr. number & Reagents/antibodies & Details \\
\hline 1 & Phosphate buffered saline & Sigma Aldrich, USA \\
\hline 2 & Fetal calf serum & Sigma Aldrich, USA \\
\hline 3 & Penicillin and streptomycin & Sigma Aldrich, USA \\
\hline 4 & DMEM & Sigma Aldrich, USA \\
\hline 5 & $0.25 \%$ trypsin-EDTA & Sigma Aldrich, USA \\
\hline 6 & Crystal violet dye & Sigma Aldrich, USA \\
\hline 7 & Fetal bovine serum & Sigma Aldrich, USA \\
\hline 8 & HAM F12 & Sigma Aldrich, USA \\
\hline 9 & Hydrocortisone & Sigma Aldrich, USA \\
\hline 10 & Insulin transferrin & Sigma Aldrich, USA \\
\hline 11 & DAPI & Sigma Aldrich, USA \\
\hline 12 & CK5 antibody & Sigma Aldrich, USA \\
\hline 13 & CK10 antibody & Sigma Aldrich, USA \\
\hline 14 & Involucrin antibody & Sigma Aldrich, USA \\
\hline 15 & Insulin & Sigma Aldrich, USA \\
\hline 16 & $\begin{array}{l}\text { Basic fibroblast growth } \\
\text { factor }\end{array}$ & Sigma Aldrich, USA \\
\hline 17 & Trizol reagent & Sigma Aldrich, USA \\
\hline 18 & Reverse transcriptase kit & Invitrogen, USA \\
\hline 19 & Keratinocytes growth factor & Invitrogen, USA \\
\hline 20 & CD45 antibody & Abcam, UK \\
\hline 21 & CK8 antibody & Abcam, UK \\
\hline 22 & CK18 antibody & Abcam, UK \\
\hline 23 & CK19 antibody & Abcam, UK \\
\hline 24 & CD49 antibody & Abcam, UK \\
\hline 25 & CD73 antibody & Abcam, UK \\
\hline 26 & CD90 antibody & Abcam, UK \\
\hline 27 & FAP- $\alpha$ antibody & Abcam, UK \\
\hline 28 & Loricrin antibody & Abcam, UK \\
\hline 29 & Collagen-3 antibody & $\begin{array}{c}\text { Santa Cruz } \\
\text { Biotechnology, USA }\end{array}$ \\
\hline 30 & Desmin antibody & $\begin{array}{c}\text { Santa Cruz } \\
\text { Biotechnology, USA }\end{array}$ \\
\hline 31 & E-Cadherin & $\begin{array}{c}\text { Santa Cruz } \\
\text { Biotechnology, USA }\end{array}$ \\
\hline 32 & Procollagen-1 antibody & $\begin{array}{c}\text { Santa Cruz } \\
\text { Biotechnology, USA }\end{array}$ \\
\hline
\end{tabular}

2.4.2. Differentiation of UC-MSCs into Dermal Fibroblast-Like Cells. UC-MSCs isolated from cord tissue were induced to differentiate into fibroblast-like cells at passage 2 . Briefly, $1 \times$ $10^{4}$ UC-MSCs were plated in each well of a 6 -well plate in complete expansion medium. When cells attain their normal morphology, the expansion medium was replaced with fibroblast differentiation medium (DMEM supplemented with 10\% FCS (Sigma Aldrich, USA)), $100 \mathrm{IU} / \mathrm{mL}$ penicillin, $100 \mathrm{mg} / \mathrm{mL}$ streptomycin, $5 \mathrm{ug} / \mathrm{mL}$ insulin, and $1 \mathrm{ng} / \mathrm{mL}$ basic fibroblast growth factor (Sigma Aldrich, USA). The medium was replaced twice a week for 15 days. Cells grown in expansion medium served as control. Morphological changes were observed during induction period. Further, immunostaining and RT-PCR were performed to assess differentiation into dermal fibroblast-like cells.

\subsection{Assessment of Differentiated Keratinocytes and Dermal Fibroblast-Like Cells}

2.5.1. Immunostaining. Immunostaining was performed for the expression of keratinocytes specific markers: CK5, CK10, involucrin (Sigma Aldrich, USA), and loricrin (Abcam, UK) and dermal fibroblast specific markers, collagen-3 (Santa Cruz Biotechnology, USA), desmin (Santa Cruz Biotechnology, USA), FAP- $\alpha$ (Abcam, UK), and procollagen-1 (Santa Cruz Biotechnology, USA). Briefly, cells were washed with PBS three times and treated with $4 \%$ paraformaldehyde (PFA) for 15 minutes. The fixed cells were washed with PBS $(5 \times 3$ times) and incubated with the primary antibodies overnight at $4^{\circ} \mathrm{C}$. Incubation at room temperature with respective secondary antibodies $(1: 200)$ was performed for 1 hour at $37^{\circ} \mathrm{C}$. After washing with PBS, cell nuclei were stained with DAPI (Sigma Aldrich, USA) and observed microscopically.

2.5.2. Reverse Transcriptase Polymerase Chain Reaction (RT$P C R$ ). Expression of lineage specific genes was carried out by RT-PCR. Briefly, cells were cultured for 15 days in the respective differentiation medium and total RNA was extracted using Trizol reagent (Sigma Aldrich, USA). RNA was quantified with a ND-1000 spectrophotometer (NanoDrop Technologies, USA). 1.5 ug of RNA sample was used for cDNA synthesis using MMLV (Moloney murine leukaemia virus) reverse transcriptase kit (Invitrogen, USA). The following PCR conditions were used: $94^{\circ} \mathrm{C}$ for 5 minutes followed by 35 cycles for $45 \mathrm{sec}$ at $94^{\circ} \mathrm{C}, 45 \mathrm{sec}$ at respective annealing temperature (mentioned against each gene), and $72^{\circ} \mathrm{C}$ for $45 \mathrm{sec}$. RT-PCR for cells differentiated into keratinocytes-like cells was done for the expression of CK1 $\left(57^{\circ} \mathrm{C}\right), \mathrm{CK} 10\left(57^{\circ} \mathrm{C}\right)$, $\mathrm{CK} 14\left(58^{\circ} \mathrm{C}\right)$, and E-Cad. $\left(57^{\circ} \mathrm{C}\right)$ while for cells differentiated into dermal fibroblast-like cells it was done using collagen$3\left(59^{\circ} \mathrm{C}\right)$, desmin $\left(58^{\circ} \mathrm{C}\right), \mathrm{FGF} 7\left(58^{\circ} \mathrm{C}\right)$, and vimentin $\left(57^{\circ} \mathrm{C}\right)$. Beta actin was used as an internal control. Sequences for the primer pairs and their product lengths (bp) are given in Table 1. Gel bands were quantified with image J software (http://rsbweb.nih.gov/ij/).

2.6. Statistical Analysis. Statistical analysis of data was performed using Graphpad prism 5 software. The data was presented as mean \pm standard deviation. Unpaired $t$-test was performed to compare two groups. $P$ values $\leq 0.05$ were considered to be statistically significant.

\section{Results}

3.1. Biological Properties of AECs and UC-MSCs. Cells from amniotic membrane and cord tissue were successfully isolated. Cell outgrowth from both types of tissues was observed in 3-4 days after culturing. Epithelial cells were round in shape (Figure 1(a)) while UC-MSCs showed spindle shaped morphology (Figure 1(b)). Both types of cells were plastic 


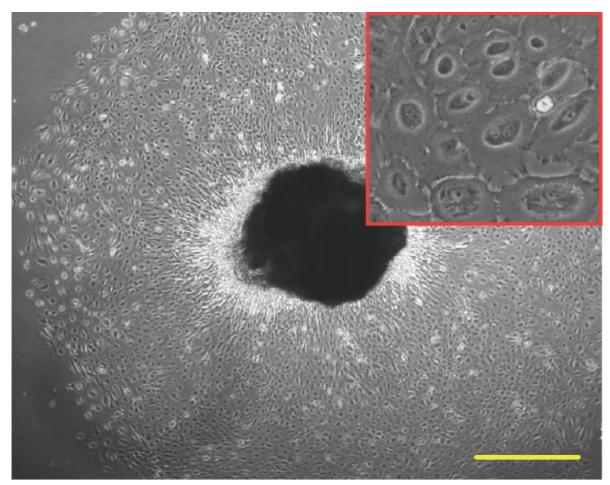

(a)

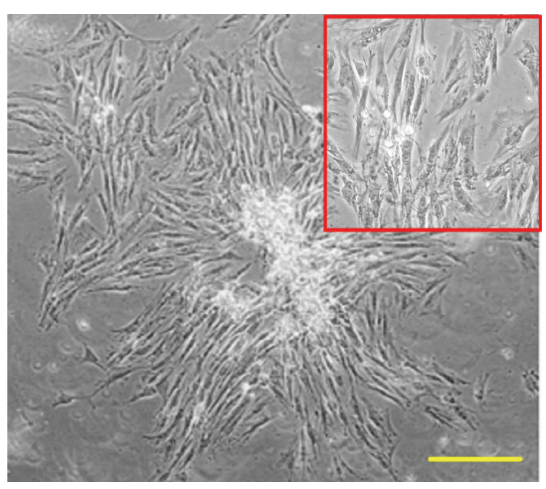

(b)

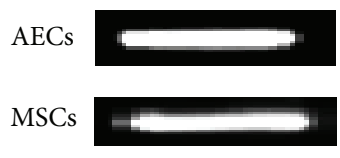

Beta actin

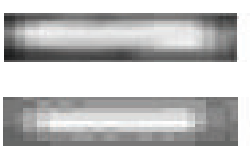

SSEA4

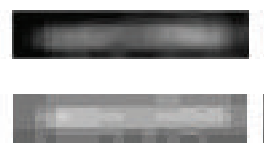

NANOG

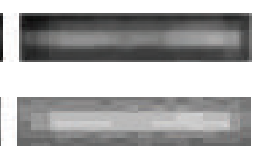

OCT4

(c)

FIGURE 1: Morphological appearance of human amniotic epithelial cells (AECs) and umbilical cord mesenchymal stem cells (UC-MSCs). Cells in the primary culture of AECs (a) and UC-MSCs (b). AECs displayed rounded shape while UC-MSCs showed spindle shaped morphology. Insets show morphological features at higher magnification. Both types of cells showed expression of embryonic lineage markers SSEA4, NANOG, and OCT4 (c). AECs: amniotic epithelial cells, UC-MSCs: mesenchymal stem cells, SSEA4: stage specific embryonic antigen 4, and OCT4: octamer binding protein 4 .

adherent and grew into colonies; however, colonies of AECs were more like a sheet of cells. The neonatal origin of both sources was confirmed by RT-PCR using NANOG, OCT4, and SSEA4 (Figure 1(c)). The results of the current study are in line with previous studies that show similar findings [8-11].

\subsection{Characterization of Cells. AECs and UC-MSCs were} characterized at passage 2 using immunostaining and RTPCR. Both types of cells were negative for hematopoietic marker CD45 (Figures 2 and 3). AECs were positive for CK8, CK18, and CK19 using immunostaining (Figures 2(a)2(e)) and CK16, CK18, CK19, and E-Cadherin using RT-PCR analysis (Figure 2(f)). Our results are in line with previous reports in this regard $[12,13]$. UC-MSCs were positive for mesenchymal lineage markers CD49, CD73, and CD90 using immunostaining and CD29, CD44, CD73, and CD90 as indicated by RT-PCR (Figures 3(a)-3(e) and 3(f)). These results are in accordance with previously published data $[6$, 14-16].

3.3. Growth Characteristics of AECs and UC-MSCs. To determine the self-renewal ability of cells, both AECs and UCMSCs were seeded in low numbers. Numbers of cells that form colonies were counted and plating efficiency was determined. Plating efficiency of AECs was $5.23 \pm 0.72$ while those of UC-MSCs were $20.41 \pm 2.33$ when 50 cells per $\mathrm{cm}^{2}$ were seeded (Table 3 ). A colony forming efficiency of $5.7 \%$ has been previously reported for passage 2 AECs, which is similar to plating efficiency found in our study. Similarly, plating efficiency of $12.53 \pm 1.45$ has been previously reported for
TABLE 3: Growth characteristics of AECs and UC-MSCs as determined by using parameters such as PDs, PDT, and PE. PDs: population doublings, PDT: population doubling time, and PE: plating efficiency.

\begin{tabular}{lccc}
\hline Biological samples & PDs & PDT (hours) & PE (\%) \\
\hline AECs & $7.3 \pm 1.34$ & $140 \pm 20$ & $5.23 \pm 0.72$ \\
MSCs & $28.12 \pm 2.5$ & $50 \pm 6.0$ & $20.4 \pm 2.33$ \\
\hline
\end{tabular}

UC-MSCs; however, this difference might be due to different number of cells plated.

We also determined maximum population doublings and doubling time for both types of cells. Number of population doublings for AECs was $7.3 \pm 1.35$ while those of UC-MSCs were $28.12 \pm 2.5$ (Table 3 ). It is noteworthy that proliferative potential of AECs is not much different in the initial passages compared to UC-MSCs; however, AECs proliferation declines in initial passages and they only proliferated for 4-6 passages [12]. Cord tissue UC-MSCs are highly proliferative as indicated in this study which is in accordance with previously published reports $[6,17]$.

\subsection{Analysis of In Vitro Differentiation Potential}

3.4.1. Amniotic Epithelial Cells Can Differentiate into Keratinocytes-Like Cells. AECs were induced to differentiate into keratinocytes-like cells at passage 2 by culturing cells for 15 days in keratinocyte differentiation medium. Differentiation into keratinocytes-like cells was confirmed by assessing morphological changes, by immunostaining, and further by RT-PCR analysis. In the induction medium epithelial 


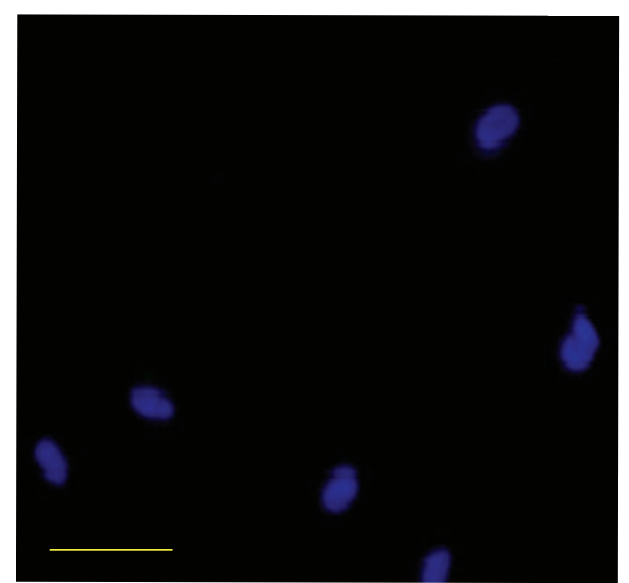

(a)

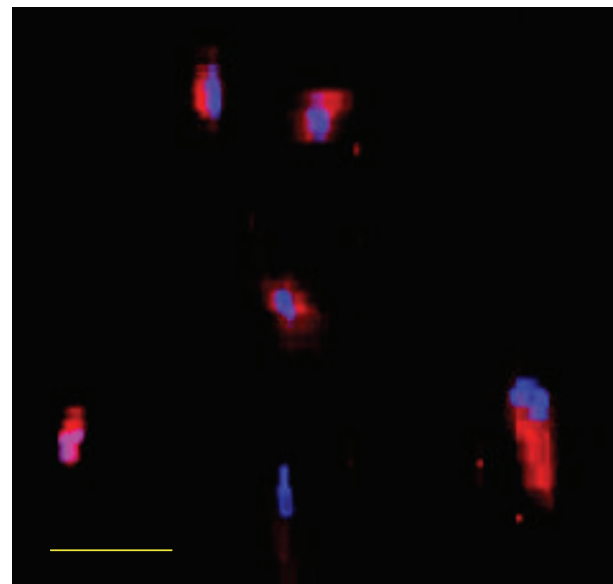

(c)

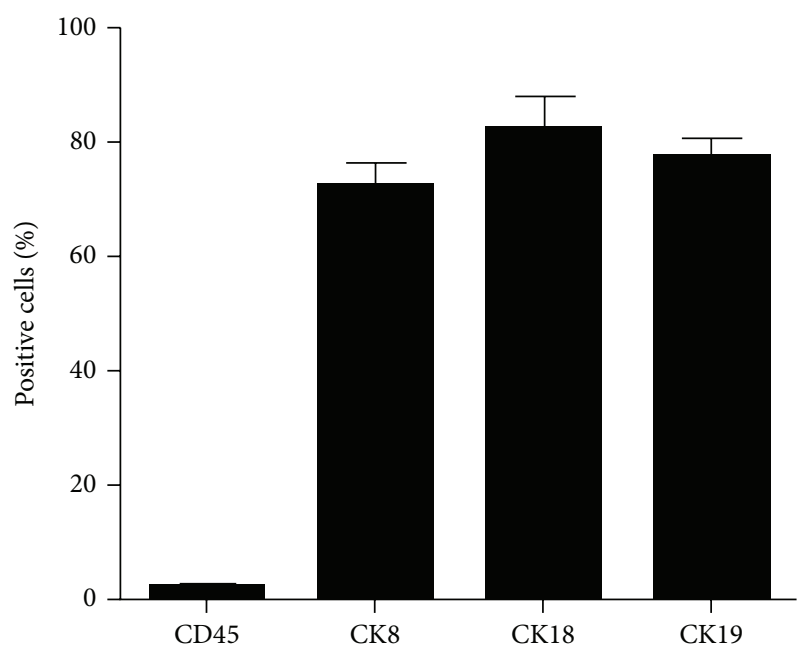

(e)

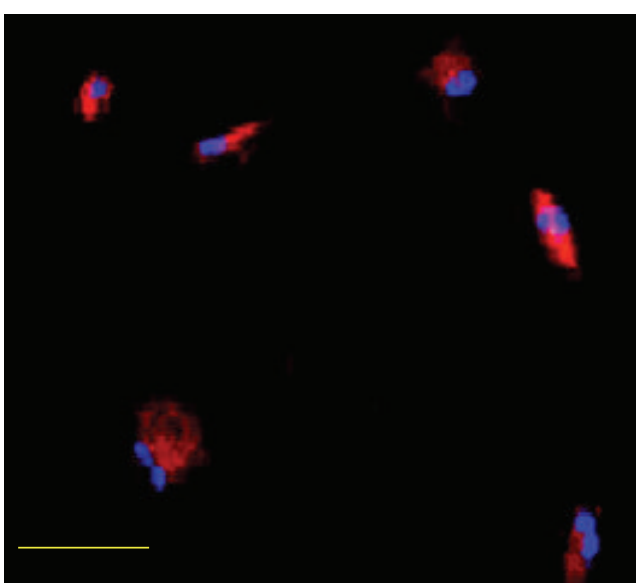

(b)

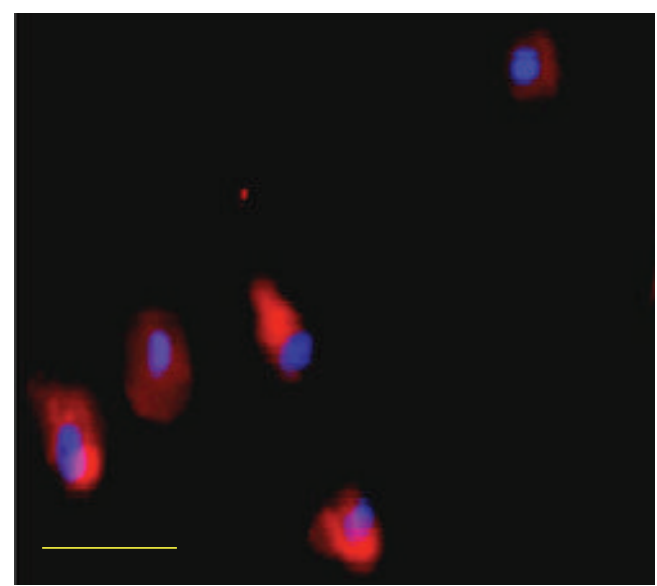

(d)

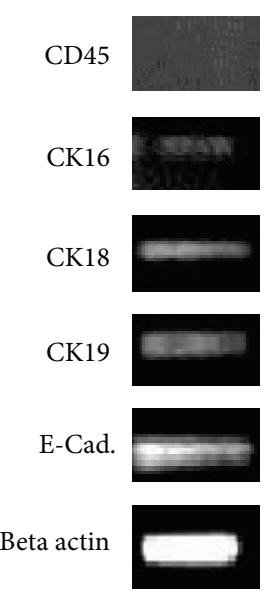

(f)

FIGURE 2: Immunostaining for AECs; (a) CD 45 negative. (b)-(d) CK8, CK18, and CK19 positive. (e) shows percentage of positive cells. RT-PCR for AECs; (f) CK16, CK18, CK19, and E-Cadherin positive. 


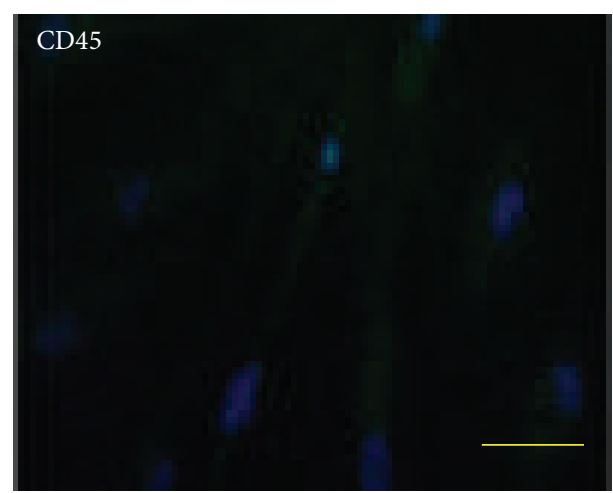

(a)

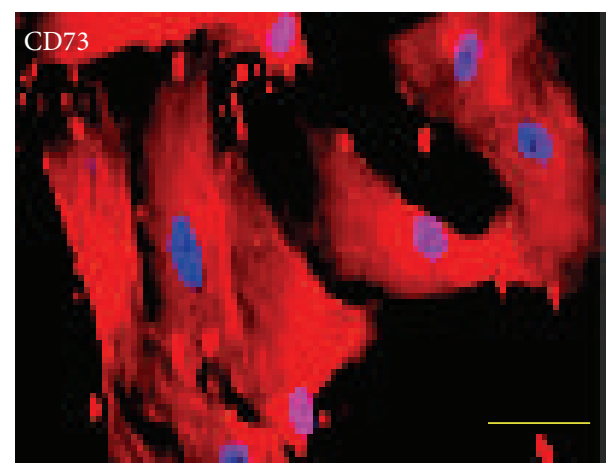

(c)

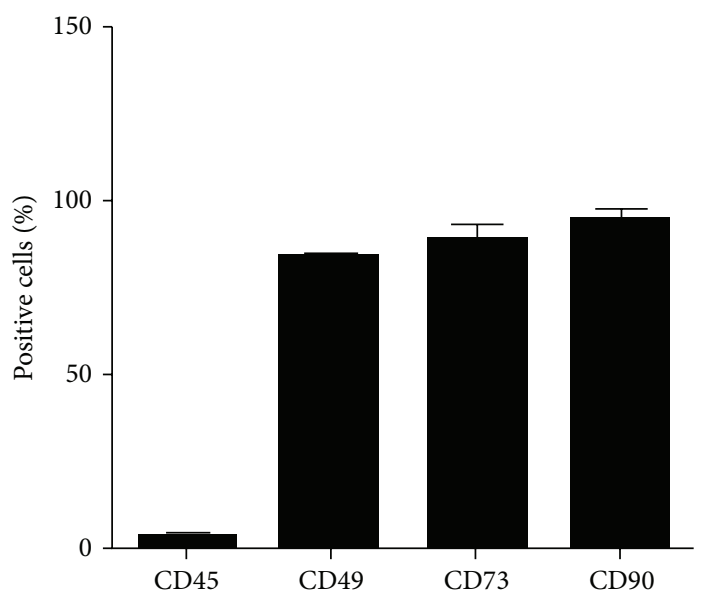

(e)

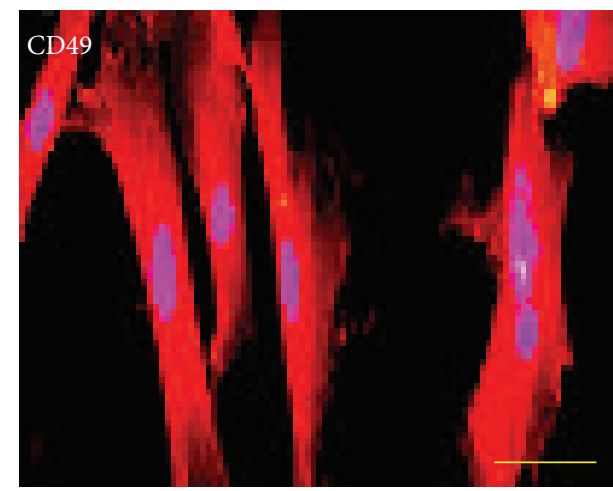

(b)

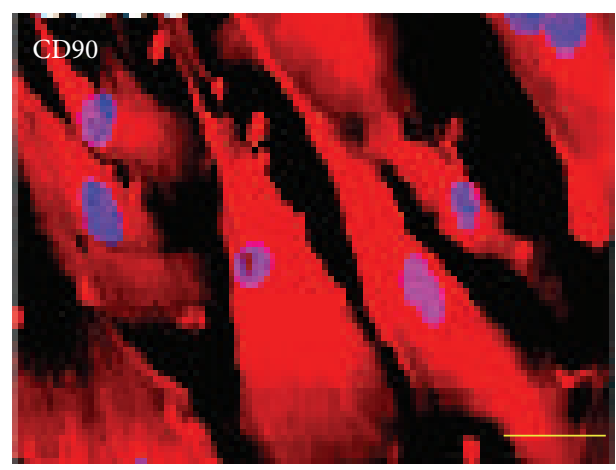

(d)

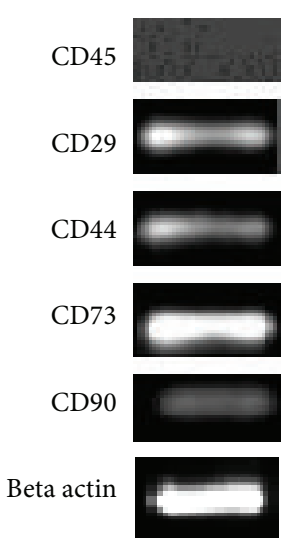

(f)

FIGURE 3: Immunostaining for UC-MSCs; (a) CD 45 negative. (b)-(d) CD49, CD73, and CD90 positive. (e) shows percentage of positive cells. RT-PCR for UC-MSCs; (f) CD29, CD44, CD73, and CD 90 positive.

cells turned from rounded to polygonal shape, characteristic of keratinocytes (Figures 4(a)-4(c)). The immunostaining results also indicated that induced cells were positive for CK5, CK10, involucrin, and loricrin (Figures 4(d) and 4(e)) specifically expressed by keratinocytes [18]. Further, the expression of keratinocyte lineage specific genes CK1, CK10, CK14, and E-Cadherin was significantly upregulated in treated cultures as compared to control (Figures 4(f) and $4(\mathrm{~g}))$. Results of this study are in accordance with other published reports that indicate upregulation of these genes in cells undergoing differentiation into keratinocytes [19].

3.4.2. Differentiation of UC-MSCs into Dermal Fibroblast-Like Cells. Differentiation of UC-MSCs was initiated at passage 2 and experiments were terminated after 15 days. Morphology of UC-MSCs in the induction medium changed considerably (Figures 5(a)-5(c)) from fibroblastic to more irregular or triangular shape [20]. Immunofluorescence staining displayed positive expression of collagen-3, desmin, FAP- $\alpha$, 


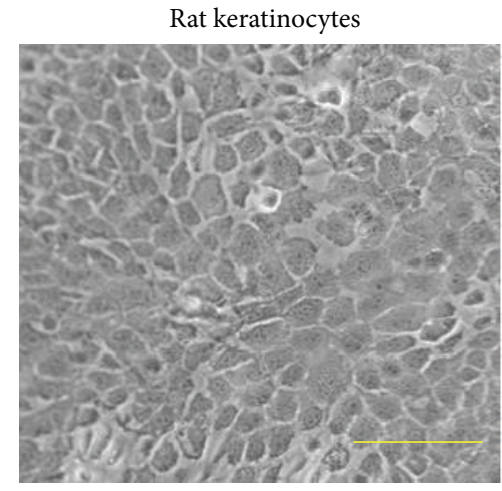

(a)

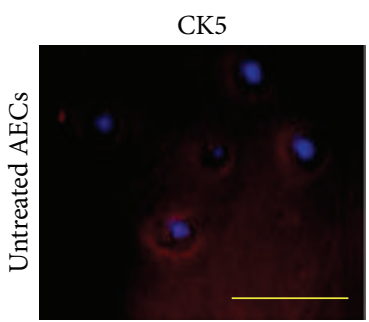

(d1)

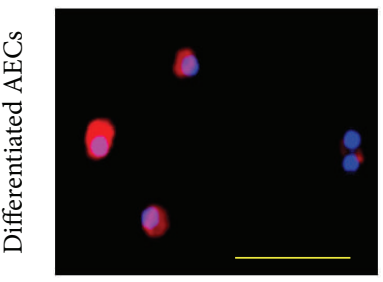

(e1)

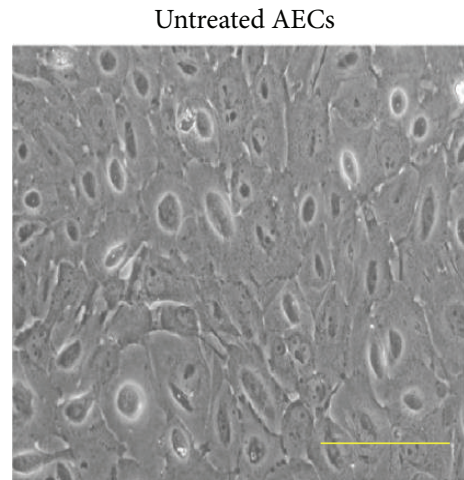

(b)

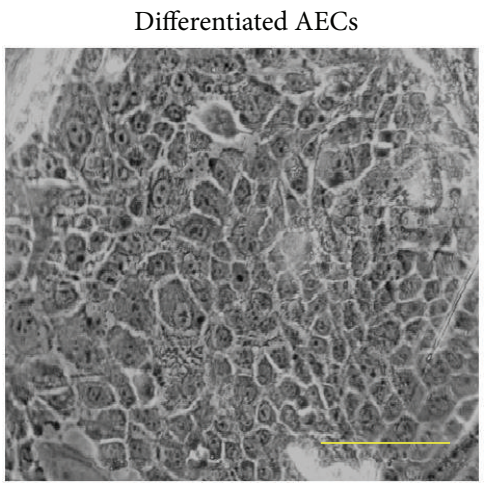

(c)

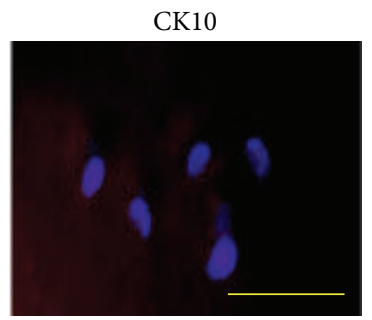

(d2)

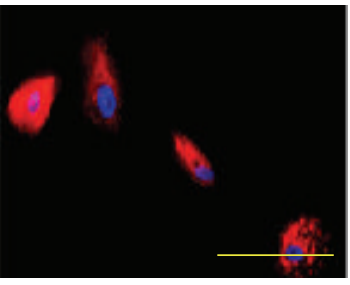

(e2)

(d)

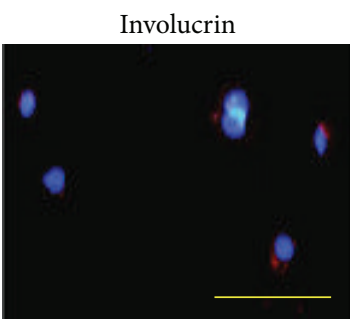

(d3)

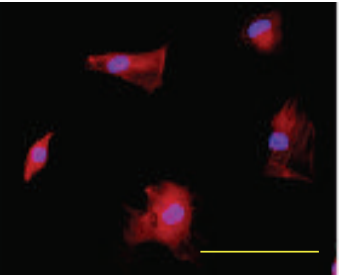

(e3)

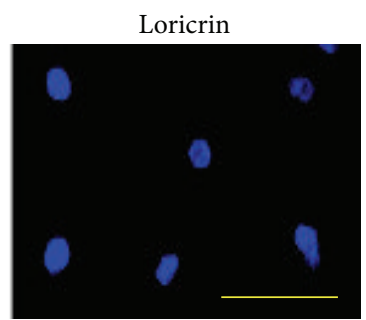

(d4)

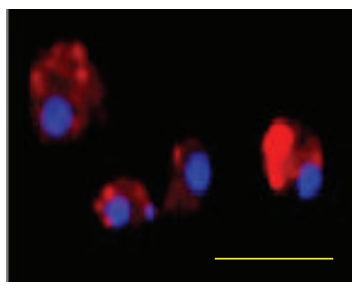

(e4)

(e)

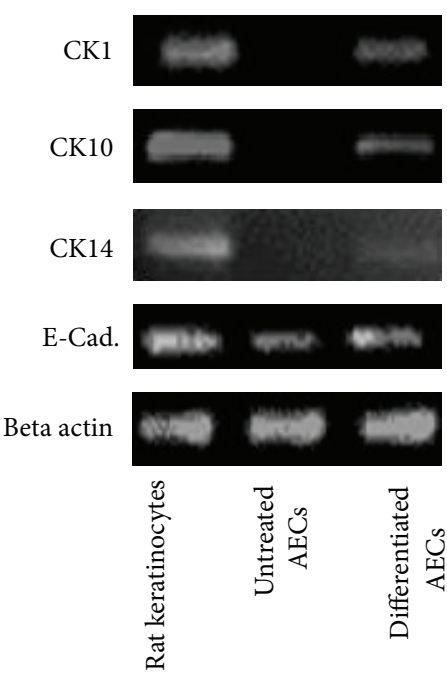

(f)

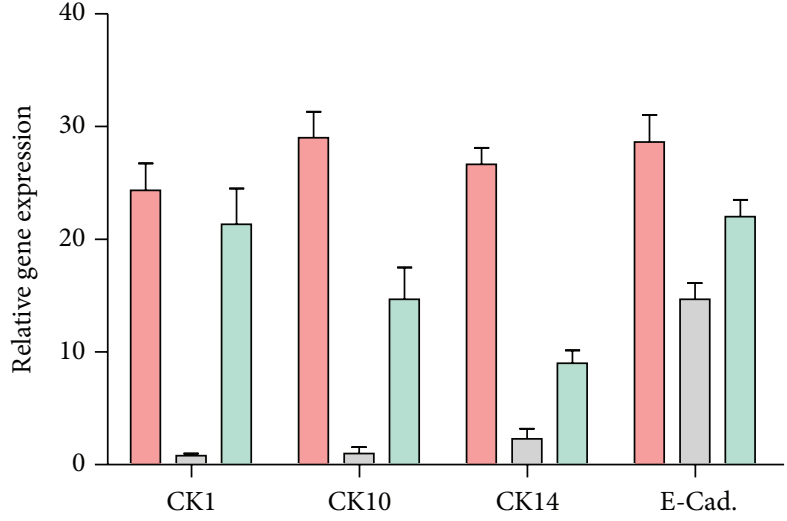

$\square$ Rat keratinocytes

$\square$ Untreated AECs

$\square$ Differentiated AECs

(g)

FIGURE 4: Differentiation potential of amniotic membrane epithelial cells into keratinocyte-like cells. Cytomorphology of (a) positive control, (b) untreated AECs, and (c) induced keratinocytes-like cells. Immunofluorescence staining with CK5, CK10, involucrin, and loricrin in ((d1)(d4)) untreated AECs and in ((e1)-(e4)) induced cells. Expression of mRNA of CK1, CK10, CK14, and E-Cadherin in positive control and untreated and treated cells has been shown in (f). Expression of these genes was significantly upregulated in treated group as compared to untreated AECs. (g) showed graphical representation of RT-PCR analysis. 
Rat fibroblasts

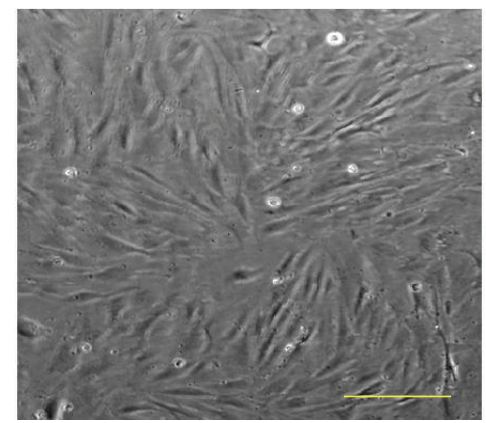

(a)

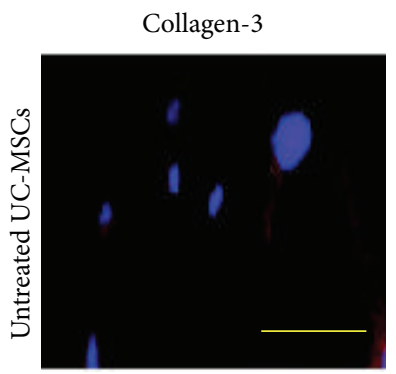

(d1)

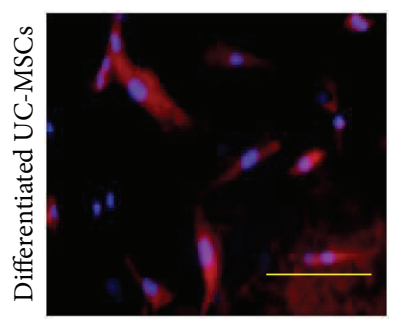

(e1)
Untreated UC-MSCs

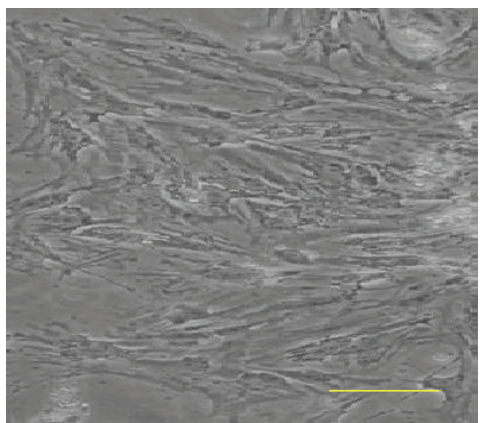

(b)

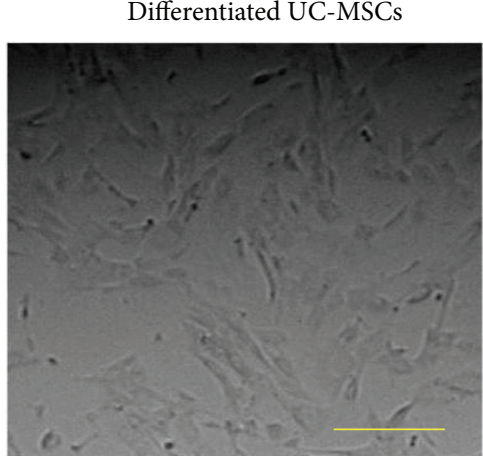

(c)

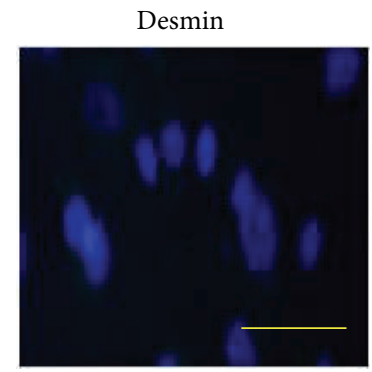

(d2)

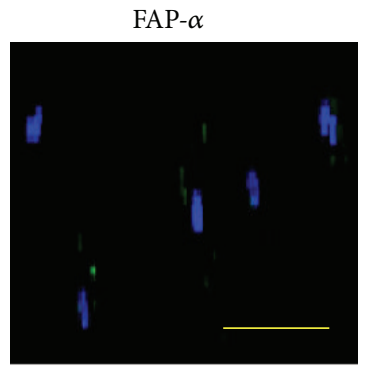

(d3)
Procollagen-1

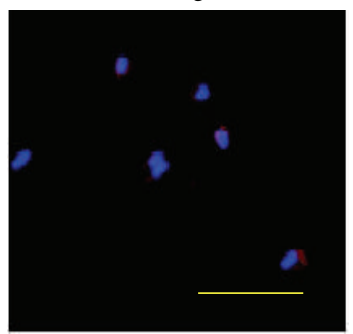

(d4)

(d)

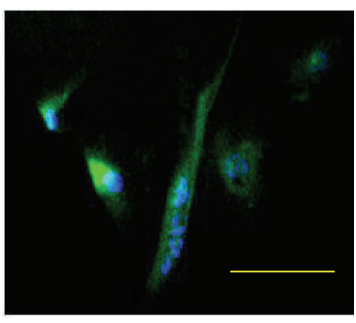

(e2)

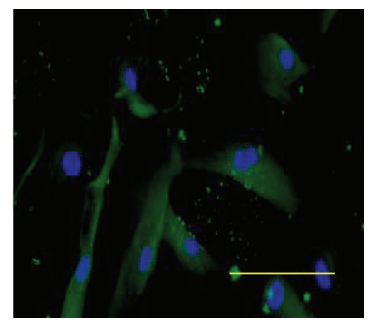

(e3)

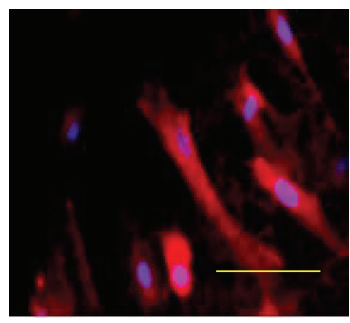

(e4)

(e)

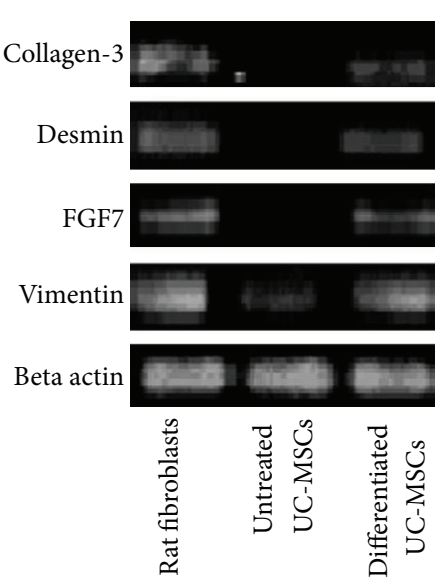

(f)

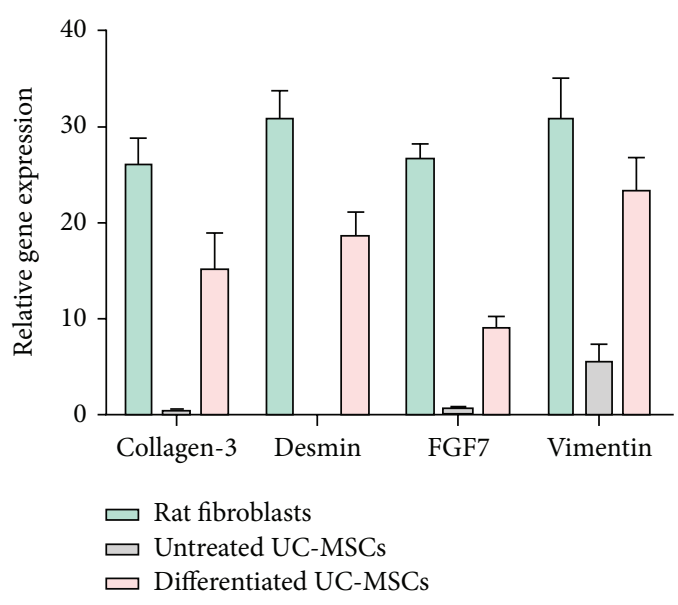

(g)

FiguRE 5: Differentiation potential of cord tissue derived UC-MSCs into dermal fibroblast-like cells. Cytomorphology of (a) positive control, (b) untreated UC-MSCs, and (c) induced dermal fibroblast-like cells. Immunofluorescence staining with collagen-3, desmin, FAP- $\alpha$, and procollagen-1 in ((d1)-(d4)) untreated UC-MSCs and in ((e1)-(e4)) induced cells. Expression of mRNA of collagen-3, desmin, FGF7, and vimentin has been shown in (f). Expression of these genes was significantly upregulated in induced cells as compared to untreated cells. Collagen-3: collagen type 3, FGF7: fibroblast growth factor 7, FAP- $\alpha$ : fibroblast activation protein-alpha, and procollagen-1: procollagen type 1. (g) showed graphical representation of RT-PCR analysis. 
and procollagen-1 (Figures 5(d) and 5(e)). These markers are highly expressed in dermal fibroblasts [20-22]. Differentiation at the mRNA level was also observed and results indicated upregulation of collagen-3, desmin, FGF-7, and vimentin (Figures 5(f) and 5(g)).

\section{Discussion}

Parts of the placenta such as amniotic membrane and Wharton's jelly have a long history of their use in diagnostic applications. Cell populations in both amniotic membrane and Wharton's jelly are easily accessible and nontumorigenic and have ability to differentiate into variety of cell types. These characteristics have stimulated a flurry of research that aim at characterizing and evaluating their potential for use in tissue engineering and regenerative medicine. Regenerative medicine involves the use of cells to repair or replace damaged tissues for the restoration of their normal function. Stem cells are promising candidates for use in tissue engineering and regenerative medicine applications as they possess unique characteristics of self-renewal and differentiation into variety of cell types. Stem cells are present in various adult and neonatal tissues. Although adult stem cells have fewer ethical restrictions and reduced chances of teratoma formation their number, proliferation, and differentiation are limited [23, 24] making a serious limitation for use in cell-based therapy. Similarly, embryonic and induced pluripotent stem cells have problems such as legal and ethical considerations and genomic instability $[25,26]$. Due to these drawbacks much attention has been paid to find alternative sources of cells for use in tissue engineering and regenerative medicine. In contrast to adult tissues, harvesting cells from neonatal sources (such as placental tissue) is a noninvasive procedure without risks to donors. Therefore, the current study was designed to evaluate the differentiation potential of human placenta derived stem cells into skin cells in an effort to appraise the potential use of these cells for the regeneration of burn injured skin.

In the present study we successfully isolated and characterized two types of stem cells from the placental tissue: epithelial cells from the amniotic membrane and UC-MSCs from cord tissue. Epithelial cells were then differentiated in vitro into the keratinocytes-like cells and UC-MSCs into dermal fibroblasts. Both enzymatic $[8,9]$ and nonenzymatic [6] methods have been suggested for isolation of cells from cord tissue and amniotic membrane. However, we selected nonenzymatic digestion method as it is simple, efficient, and inexpensive. Both types of cells displayed plastic adherent growth and cell outgrowth was observed 3-4 days after culturing. UC-MSCs showed characteristic fibroblast-like morphology similar to that observed with bone marrow derived MSCs [17]. The morphological features of AECs have been reported to be similar to other epithelial cells such as respiratory epithelial cells [27] with round morphology. Both UC-MSCs and AECs grew into colonies when seeded in low numbers; however, AECs raised more like a sheet of cells attached to plastic surface especially the cells from primary culture. As expected, based on previous reports, cells isolated from amniotic membrane and cord tissue showed expression of OCT4, NANOG, and SSEA4 which are stemness markers associated with embryonic origin [8-11, 28]. UC-MSCs revealed positive expression of MSC markers CD29, CD44, CD49, CD73, and CD90. Similarly, epithelial cells obtained from amniotic membrane were positive for CK8, CK16, CK18, and CK19. Both types of cells were negative for hematopoietic marker, CD45, as determined by immunostaining and RTPCR. This analysis showed that there was no contamination of hematopoietic stem cells from cord blood.

Previously, we and others have shown that UC-MSCs derived from cord tissue have multilineage differentiation potential. In the current study, AECs expressed morphology of keratinocytes after in vitro induction. Immunostaining results indicated that differentiated cells were positive for the expression of CK5, CK10, involucrin, and loricrin. Differentiation into keratinocyte-like cells was further confirmed by significantly upregulated mRNA levels of CK1, CK10, CK14, and E-Cad. genes observed in induced cultures compared to controls.

UC-MSCs were induced to differentiate into dermal fibroblasts at passage 2 . In the induction medium, differentiated cells showed changes in their morphology. Moreover, immunostaining of induced cells showed strongly positive expression of collagen-3, desmin, FAP- $\alpha$, and procollagen. Similarly, upregulation of desmin, FGF7, and vimentin as measured with quantitative PCR further confirmed differentiation of UC-MSCs into dermal fibroblasts. These findings indicate that UC-MSCs could be induced to differentiate into dermal fibroblasts in vitro and could be used as seed cells for reconstructing off the shelf skin products to be used for skin engineering.

\section{Conclusion}

In conclusion, AECs and UC-MSCs can be induced to differentiate into keratinocytes and fibroblasts in vitro.

\section{Abbreviations \\ AECs: Amniotic epithelial cells \\ UC-MSCs: Umbilical cord mesenchymal stem cells \\ CK: $\quad$ Cytokeratin \\ DMEM: Dulbecco's modified eagle medium.}

\section{Disclosure}

The funding body did not play any role in performing the experiments, in writing the paper, or in submission of paper.

\section{Conflict of Interests}

The authors declare that there is no conflict of interests regarding the publication of this paper.

\section{Authors' Contribution}

Ruhma Mahmood and Mahmood S. Choudhery designed the study, performed experiments, and drafted the paper. 
Azra Mehmood, Shaheen N. Khan, and Sheikh Riazuddin performed data evaluation and critical review of the paper. All the authors contributed to the final version of the paper. Ruhma Mahmood and Mahmood S. Choudhery contributed equally.

\section{Acknowledgments}

This study was funded by the Higher Education of Pakistan. The authors would like to thank our colleagues for their suggestions and constructive criticism.

\section{References}

[1] J. Li, J. Chen, and R. Kirsner, "Pathophysiology of acute wound healing," Clinics in Dermatology, vol. 25, no. 1, pp. 9-18, 2007.

[2] A. Trautmann, G. Krohne, E.-B. Bröcker, and C. E. Klein, "Human mast cells augment fibroblast proliferation by heterotypic cell-cell adhesion and action of IL-4," Journal of Immunology, vol. 160, no. 10, pp. 5053-5057, 1998.

[3] R. B. Ahuja and S. Bhattacharya, "Burns in the developing world and burn disasters," British Medical Journal, vol. 329, no. 7463, pp. 447-449, 2004.

[4] B. P. Sarma, "Prevention of burns: 13 years' experience in Northeastern India," Burns, vol. 37, no. 2, pp. 265-272, 2011.

[5] S. Raeder, T. P. Utheim, O. A. Utheim et al., "Effect of limbal explant orientation on the histology, phenotype, ultrastructure and barrier function of cultured limbal epithelial cells," Acta Ophthalmologica Scandinavica, vol. 85, no. 4, pp. 377-386, 2007.

[6] M. S. Choudhery, M. Badowski, A. Muise, and D. T. Harris, "Comparison of human mesenchymal stem cells derived from adipose and cord tissue," Cytotherapy, vol. 15, no. 3, pp. 330-343, 2013.

[7] M. S. Choudhery, M. Khan, R. Mahmood, A. Mehmood, S. N. Khan, and S. Riazuddin, "Bone marrow derived mesenchymal stem cells from aged mice have reduced wound healing, angiogenesis, proliferation and anti-apoptosis capabilities," Cell Biology International, vol. 36, no. 8, pp. 747-753, 2012.

[8] Y. Y. Chen, Y. Lu, K. Wang et al., "Optimization of in vitro culture conditions for human amniotic epithelial cells and expression of stem cell markers," Zhongguo Shi Yan Xue Ye Xue Za Zhi, vol. 19, pp. 464-468, 2011.

[9] N. Wajid, A. Mehmood, F.-U. Bhatti, S. N. Khan, and S. Riazuddin, "Lovastatin protects chondrocytes derived from Wharton's jelly of human cord against hydrogen-peroxideinduced in vitro injury," Cell and Tissue Research, vol. 351, no. 3, pp. 433-443, 2013.

[10] T. Miki, T. Lehmann, H. Cai, D. B. Stolz, and S. C. Strom, "Stem cell characteristics of amniotic epithelial cells," Stem Cells, vol. 23, no. 10, pp. 1549-1559, 2005.

[11] T. Miki, F. Marongiu, E. Ellis, and C. S. Strom, "Isolation of amniotic epithelial stem cells," Current Protocols in Stem Cell Biology, chapter 1:unit 1E 3, 2007.

[12] S. S. Fatimah, S. L. Ng, K. H. Chua, A. R. Hayati, A. E. Tan, and G. C. Tan, "Value of human amniotic epithelial cells in tissue engineering for cornea," Human Cell, vol. 23, no. 4, pp. 141-151, 2010.

[13] S. S. Fatimah, G. C. Tan, K. Chua, A. E. Tan, A. G. Nur Azurah, and A. R. Hayati, "Effects of keratinocyte growth factor on skin epithelial differentiation of human amnion epithelial cells," Burns, vol. 39, no. 5, pp. 905-915, 2013.
[14] L. Ma, B.-L. Cui, X.-Y. Feng et al., "Biological characteristics of human umbilical cord-derived mesenchymal stem cells and their differentiation into neurocyte-like cells," Zhonghua Er Ke Za Zhi, vol. 44, no. 7, pp. 513-517, 2006.

[15] G. Pratama, V. Vaghjiani, J. Y. Tee et al., "Changes in culture expanded human amniotic epithelial cells: implications for potential therapeutic applications," PLoS ONE, vol. 6, no. 11, Article ID e26136, 2011.

[16] P. Burra, D. Arcidiacono, D. Bizzaro et al., "Systemic administration of a novel human umbilical cord mesenchymal stem cells population accelerates the resolution of acute liver injury," $B M C$ Gastroenterology, vol. 12, article 88, 2012.

[17] P. Shetty, K. Cooper, and C. Viswanathan, "Comparison of proliferative and multilineage differentiation potentials of cord matrix, cord blood, and bone marrow mesenchymal stem cells," Asian Journal of Transfusion Science, vol. 4, no. 1, pp. 14-24, 2010.

[18] A. F. Laplante, L. Germain, F. A. Auger, and V. Moulin, "Mechanisms of wound reepithelialization: hints from a tissueengineered reconstructed skin to long-standing questions," The FASEB Journal, vol. 15, no. 13, pp. 2377-2389, 2001.

[19] M. Alkhalaf, G. Ganguli, N. Messaddeq, M. Le Meur, and B. Wasylyk, "MDM2 overexpression generates a skin phenotype in both wild type and p53 null mice," Oncogene, vol. 18, no. 7, pp. 1419-1434, 1999.

[20] Y. Han, J. Chai, T. Sun, D. Li, and R. Tao, "Differentiation of human umbilical cord mesenchymal stem cells into dermal fibroblasts in vitro," Biochemical and Biophysical Research Communications, vol. 413, no. 4, pp. 561-565, 2011.

[21] K. Dienus, A. Bayat, B. F. Gilmore, and O. Seifert, "Increased expression of fibroblast activation protein-alpha in keloid fibroblasts: implications for development of a novel treatment option," Archives of Dermatological Research, vol. 302, no. 10, pp. 725-731, 2010.

[22] J. Choi, M. L. Costa, C. S. Mermelstein, C. Chagas, S. Holtzer, and H. Holtzer, "MyoD converts primary dermal fibroblasts, chondroblasts, smooth muscle, and retinal pigmented epithelial cells into striated mononucleated myoblasts and multinucleated myotubes," Proceedings of the National Academy of Sciences of the United States of America, vol. 87, no. 20, pp. 7988-7992, 1990.

[23] M. Mimeault and S. K. Batra, "Concise review: recent advances on the significance of stem cells in tissue regeneration and cancer therapies," Stem Cells, vol. 24, no. 11, pp. 2319-2345, 2006.

[24] J. Hipp and A. Atala, "Sources of stem cells for regenerative medicine," Stem Cell Reviews, vol. 4, no. 1, pp. 3-11, 2008.

[25] M. A. Blasco, M. Serrano, and O. Fernandez-Capetillo, "Genomic instability in iPS: time for a break," The EMBO Journal, vol. 30, no. 6, pp. 991-993, 2011.

[26] D. A. Robinton and G. Q. Daley, "The promise of induced pluripotent stem cells in research and therapy," Nature, vol. 481, no. 7381, pp. 295-305, 2012.

[27] N. A. A. Noruddin, A. B. Saim, K. H. Chua, and R. Idrus, "Human nasal turbinates as a viable source of respiratory epithelial cells using co-culture system versus dispase dissociation technique," Laryngoscope, vol. 117, no. 12, pp. 2139-2145, 2007.

[28] S. F. Simat, K. H. Chua, H. Abdul Rahman, A. E. Tan, and G. C. Tan, "The stemness gene expression of cultured human amniotic epithelial cells in serial passages," Medical Journal of Malaysia, vol. 63, supplement, pp. 53-54, 2008. 

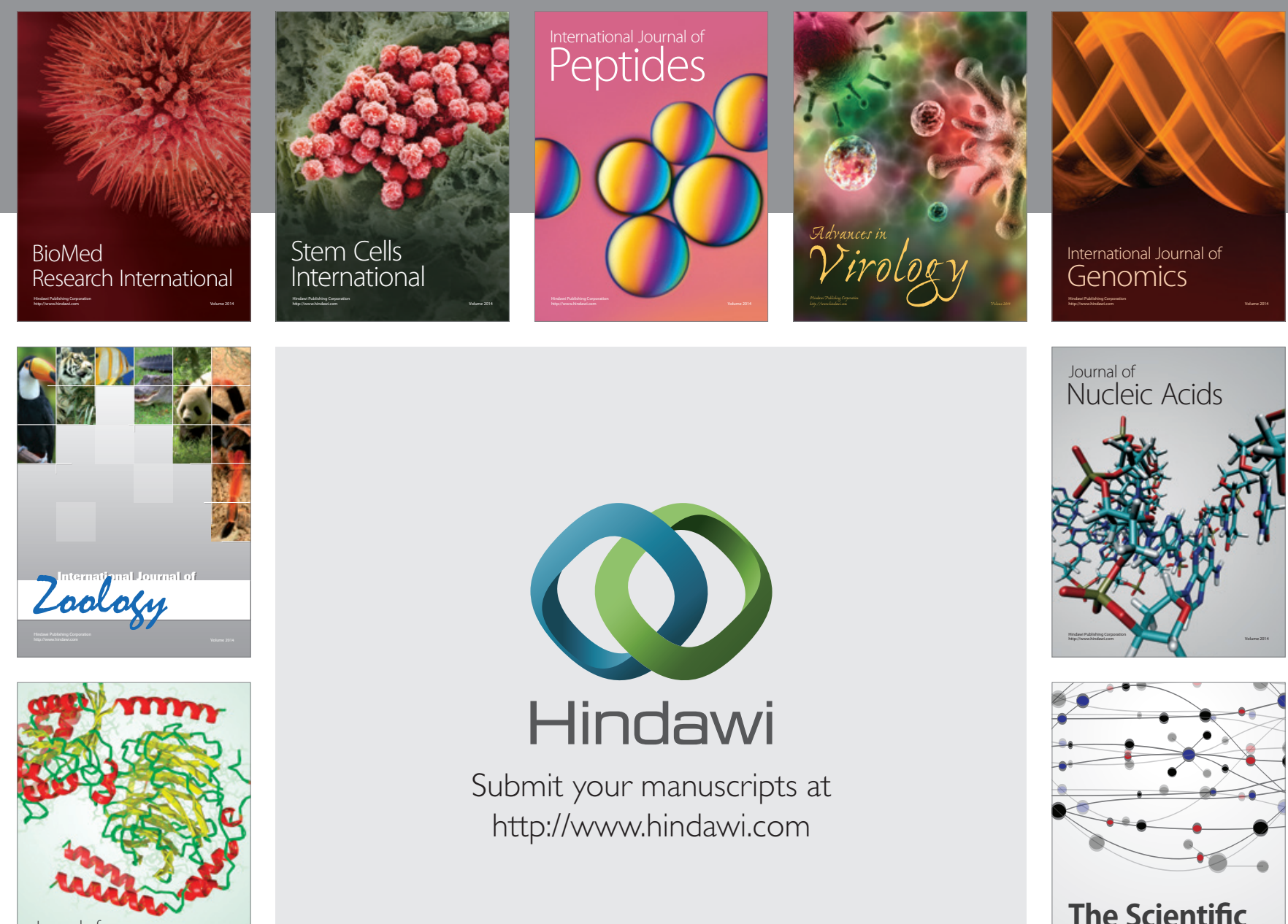

Submit your manuscripts at

http://www.hindawi.com

Journal of
Signal Transduction
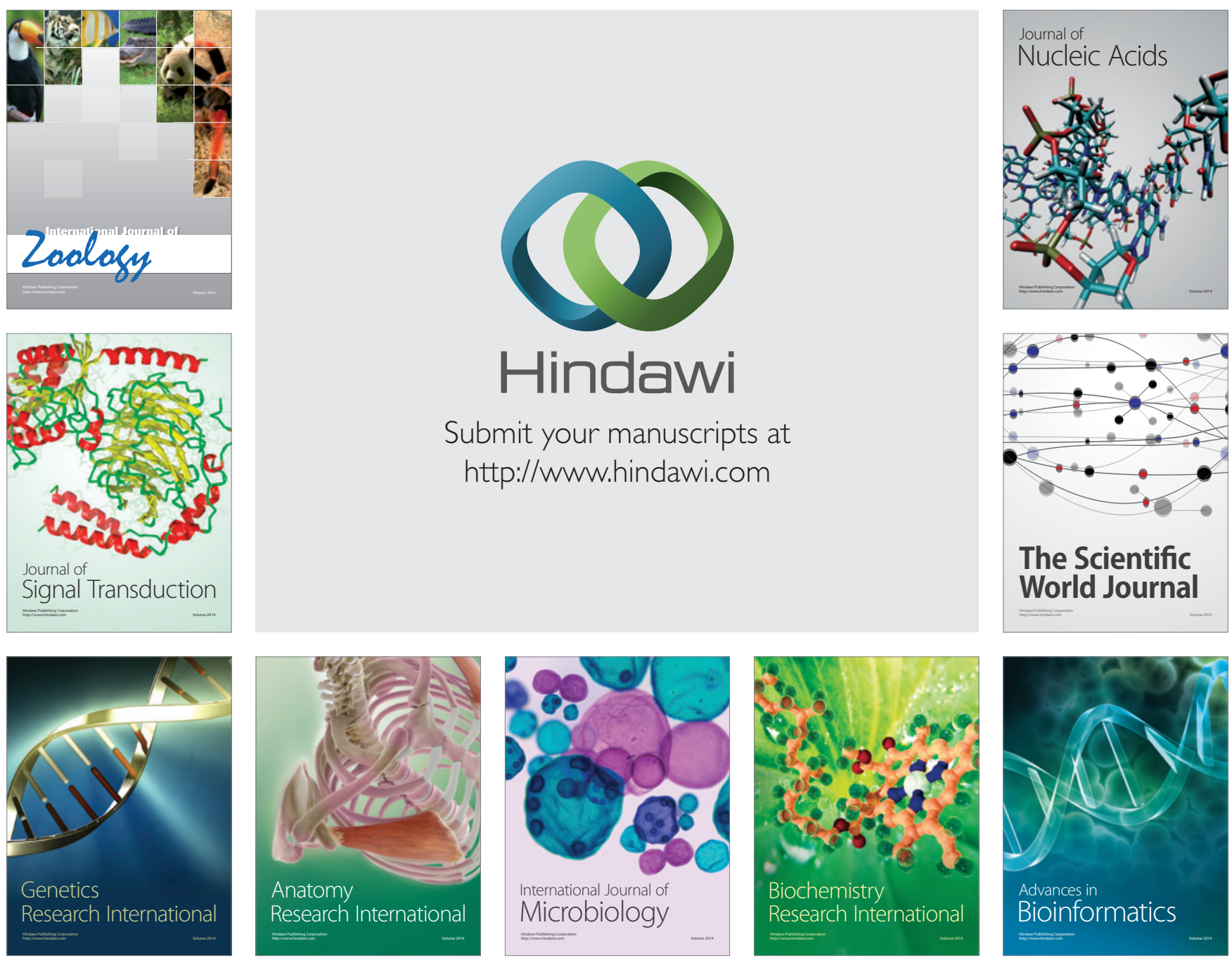

The Scientific World Journal
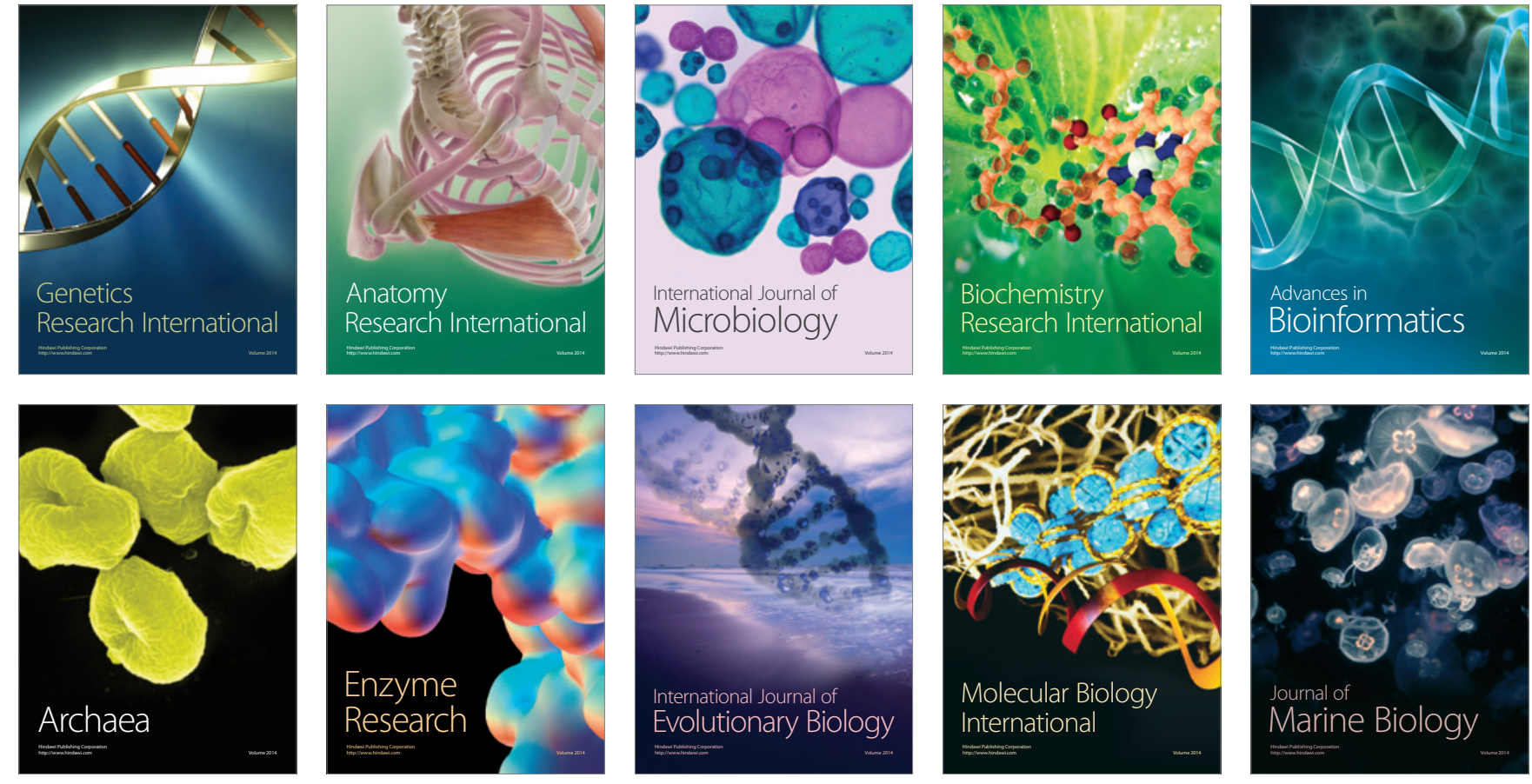